\title{
Research on Policy Regulation and Realization Path of Ningxia's Construction of All-for-One Tourism Demonstration Zone
}

\author{
Di Tian, Meifan Wu, Mu Zhang \\ Shenzhen Tourism College, Jinan University, Shenzhen, China \\ Email: hnjytdd01@163.com, zhangmu@jnu.edu.cn
}

How to cite this paper: Tian, D., Wu, M.F. and Zhang, M. (2018) Research on Policy Regulation and Realization Path of Ningxia's Construction of All-for-One Tourism Demonstration Zone. Modern Economy, 9, 1533-1547.

https://doi.org/10.4236/me.2018.99097

Received: August 21, 2018

Accepted: September 16, 2018

Published: September 19, 2018

Copyright $(9) 2018$ by authors and Scientific Research Publishing Inc. This work is licensed under the Creative Commons Attribution International License (CC BY 4.0).

http://creativecommons.org/licenses/by/4.0/

\section{(c) (i) Open Access}

\begin{abstract}
Located at the key spot of the construction of the Silk Road Economic Belt, Ningxia Hui Autonomous Region has abundant natural and cultural resources with relatively small area and small population, and tourism here plays an important role in local economic development. As China vigorously promoted the construction of tourism throughout the nation, the local government actively responded to the call of the state and successfully became the second state-level all-for-one tourism demonstration zone on a province basis, and finally achieved some decent results. In order to summarize the experience on tourism policy of Ningxia, by introducing Nvivo implementation analysis tool, this paper analyzes and summarizes a series of policy documents for the construction of demonstration zone in Ningxia. According to the specific requirements in the Guideline on the Development of All-for-One Tourism released by the State Council, the article encodes the specific policy measures for Ningxia's development and establishes a node system, pointing out that Ningxia's policy measures are consistent with the ones formulated at the national level. On this basis, taking the Xixia District of Yinchuan in Ningxia Hui Autonomous Region as an example, the paper analyzes its specific measures and effects of developing regional tourism, and discusses the policy regulation and implementation path that means taking planning and guidance seriously, emphasizing concrete implementation, promoting industrial integration, and paying close attention to tourism supervision.
\end{abstract}

\section{Keywords}

All-for-One Tourism, Policy Analysis, Qualitative Research, Ningxia

\section{Introduction}

Since the 18th National Congress of the Communist Party of China, Chairman 
$\mathrm{Xi}$ has made important instructions on the development of tourism with a comprehensive strategic vision, emphasizing that tourism is a comprehensive industry and an important driving force for economic development. The importance of tourism has risen to the state-strategic level. At the same time, with the development of social economy, China has entered the era of mass tourism with all-for-one tourism comes into being. All-for-one tourism refers to the concept to guide the transformation and upgrading of tourist destinations, ecological environment, public services, institutional mechanisms, policies and regulations, and civilized qualities, social co-construction, etc., which can coordinate economic and social development at the same time. In this case, various localities have issued corresponding policy to adapt to the local conditions and vigorously develop all-for-one tourism in response to the calls.

As the only Hui Autonomous Region in China, Ningxia has unique diverse natural and cultural tourism resources to boost the local development of tourism. After the release of the all-for-one tourism strategy, the local government quickly seized the opportunity of Ningxia development, and selected appropriate regions to actively declare the establishment of demonstration zone where it got the strategic position on the Silk Road Economic Belt.

After the initial attempt, taking advantage of the small area and small population, Ningxia Hui Autonomous Region became the second one which was put on the list of building state-level tourism demonstration zone after Hainan province. The establishment of the all-for-one tourism demonstration zone can enhance the comprehensive strength and influence of Ningxia, and provide a continuous source of power for the development of Ningxia. Meanwhile, it is also of great significance to the promotion of all-for-one tourism development in the rest of mainland in China. Hainan province is the leading pioneer in the exploration and practice of building demonstration area, while Ningxia will effect a marked impact on nationwide tourism and economic and social development.

In this context, Ningxia Hui Autonomous Region has successively issued a series of policy measures such as the "Thirteenth Five-Year All-for-one Tourism Development Plan of Ningxia Hui Autonomous Region" to continuously optimize the top-level design, promote construction of the demonstration zone, which has finally made a good progress. If we can summarize the policy of Ningxia's development of all-for-one tourism, and explore its implementation path to create the demonstration zone, it will have great significance of enlightenment and reference for the tourism developing in other regions of China, which is the motivation and starting point of the paper. After carefully reviewing the relevant literature and policy materials, the author has a preliminary understanding of the issues and objects in this research. Since Ningxia's work of tourism is a great treasure, the author carefully collected the relevant policy and documents on the development of Ningxia's all-for-one tourism, combining with the "Guiding Opinions on Promoting the Development of All-for-one Tourism" issued by the State Council and conducted text mining and qualitative 
analysis on the policy of Ningxia's construction of the all-for-one tourism demonstration zone by employing the Nvivo 11 qualitative analysis software. The following issues will be discussed:

1) According to the "Guiding Opinions on Promoting the Development of All-for-one Tourism", the Nvivo 11 Qualitative Analysis Software is used to analyze and summarize the all-for-one tourism policy of Ningxia Development, and to clarify whether the completeness of the policy measures taken by Ningxia is consistent with the national standards.

2) According to the results of the qualitative analysis and combining with the specific case of creating an all-for-one tourism demonstration zone in Yinchuan Xixia District of Ningxia, the paper summarizes and explores the path of Ningxia's development and provides the reference for the rest parts of China.

\section{Literature Review}

After the proposing of construction of all-for-one tourism, Ningxia quickly seized the opportunity resting on its own features, actively promoting the development of tourism throughout the region. It successfully became the second state-level tourism demonstration zone on a province basis. As the all-for-one tourism has received more and more attention, Ningxia's successful experience has gradually become a rare asset for other places. Based on the requirements of this paper, the author will introduce the relevant research and practice as comprehensively as possible from three aspects.

\subsection{The Development of All-for-One Tourism}

The all-for-one tourism has been rapidly popularized since it was officially put forward in 2016, and has gradually become the future direction of China's tourism development. The researches on all-for-one tourism include the core of development, the interpretation of the concept and the misunderstanding of development, which are getting deeper and deeper.

Yang Zhenzhi believes that the core connotation of development tourism is to take the tourism as the leading or guiding area in the tourism resources enrichment area, which rationally and efficiently optimizes the allocation of production factors at the space and industrial level, and to take this industry as a guide to lead the regional economic development, which continuously enhances the regional competitiveness [1]. He Jianmin believes that the basic concept of all-for-one tourism is to change tourism from a relatively smaller pattern to a larger one with the basic model converting from the scenic spot to a comprehensive area. The guiding significance of the two is mainly reflected in the fact that they generally indicate the basic features and requirements of China's tourism industry at this stage [2]. Liu Jiaming said that the current misunderstanding of all-for-one tourism development lies in the over-interpretation and dogmatic interpretation of the concept by senior officials and experts, who focused on the word of all and proposed "four-all concept (all-spot, all-service, all-time, all-people)", and made 
a fuss on the word "all". He considers that it should be well-arranged in the right region and right time with key areas and key projects. Taking everything into one hand is impossible [3]. This view points out the common misunderstandings in the current all-for-one tourism practice, which is of great significance for the further revision of the implementation path. Li Xinjian believes that the focus and future trend of all-for-one tourism development stand in the development of leisure, networking, platform and dualization [4]. Xing Jianhua and Shi Peihua started from the implementation of all-for-one tourism, pointing out that scientific and technological innovation can promote the development of all-for-one tourism from six aspects which included activating the all-for-one tourism resources stock, developing the all-for-one tourism resources increment, connecting the whole region tourism attraction elements, opening up tourism transportation system, clearing information barrier and improving the tourism management system [5].

Domestic scholars are constantly deepening and improving the research on all-for-one tourism. They have not only deeply understood the core connotation, clarifying the basic concepts and development models, but also got the hang of the misunderstandings in the practice of all-for-one tourism's development. This has an important significance for guiding the practice in various places of China, making the trend of tourism developing clearer in the future [6] [7].

\subsection{Foreign Practice of All-for-One Tourism}

It's not been long for China's all-for-one tourism, but in the continuous deepening of relevant research, people have realized that it is an inevitable trend of tourism development. Although this concept was first proposed by China, there is no shortage of similar practices in foreign countries.

Singapore, as an Asian country, is not rich in geographic tourism resources, but its tourism development level cannot be underestimated, because it attaches great importance to the integration of tourism resources. And Singapore proposed the concept of tourism unlimited, which aimed to break the traditional geographical boundaries, packed the complementary products, and strengthened the links between Singapore and other regions. All these measures make Singapore's current tourism policy actually surpass the boundaries of the narrow tourism and convey a comprehensive framework [8] [9] [10] [11] [12]. In Europe, what's worth learning for China is French construction of tourist office, the basic unit of the French Tourism Alliance institutions, whose core function is consulting and reception. As a non-government organization, France's tourism office is a bridge connecting tourism corporation and the government, which shoulders the dual responsibility of internal management and external service. It has important reference significance for the development of all-for-one tourism management in China [13] [14]. Spain's experience in developing tourism provides reference for China as well. And Spain's government has always focused on the coordinated development based on the features of the whole na- 
tion in different periods. What we should learn most is Spain's publicity and marketing strategy. Since the 1980s, the promotion of Spanish tourism experienced four stages [15] [16]. In the development, the marketing of Spanish tourism had gradually changed from tourism products to tourism culture. And its marketing strategy had been taking the whole nation as a unit and finally formed a "Spanish brand", which was deeply rooted in the hearts of all tourists.

Although foreign related practices are not named as same as the ones in China, the connotation embodied in it is consistent with the inherent requirements of all-for-one tourism. And there's a lot worth learning from China, like the comprehensive management, marketing, tourism promotion, etc. in the western developed country.

\subsection{Ningxia's Exploration for All-for-One Tourism}

The existing researches on Ningxia's all-for-one tourism summarize its practices or experiences, and provide suggestions and countermeasures based on the relevant policies and measures for Ningxia government.

Wang Kehui believes that Ningxia's cultural tourism industry is the driving force and provides a broader stage for its development. Therefore, Ningxia should focus on extending the cultural tourism chain and actively creates a cultural tourism complex [17]. Zhang Liping said that the government has played a leading role in tourism policy and marketing, and she believed that the government's leading coordination in the process of Ningxia's tourism development was indispensable [18]. This view point emphasizes the role of Ningxia in the process of building an all-for-one tourism demonstration zone. Wang Lei and other researchers analyzed the advantages and disadvantages of Ningxia's development of tourism, and summarized seven developing paths including management, resources, culture, industry, space, operation and culture, which provided a new guide for the future development [19]. Yang Fan analyzed the conditions of Ningxia by applying SWOT analysis method and confirmed that fast-developing can be achieved by optimizing the basic development level of tourism, subdividing tourism market, adjusting tourism supply structure and boosting rural tourism development [20]. Shi Peihua summarized Ningxia's exploration as "six-one" to interpret its exploration and development from the aspects of top level strategic design, which consisted of all-for-one tourism layout, implementation of comprehensive division of labor, promotion of reform and innovation, optimization of tourism services and "tourism +" industry integration [21]. From the perspective of strategic research into all-for-one tourism's promotion, Xu Lijun and others pointed out the key measures to ensure the implementation of the strategy, solve the serious shortage of tourism professionals, refresh innovation system and increase policy support [22]. The analysis and conclusions drawn from these explorations have important guiding significance ${ }^{1}$ One Integrated top-level strategic design, one overall layout of a chess game, one package of a comprehensive division of labor, one road for reform, one comprehensive optimization of tourism services, one integrated industries of tourism + . 
for the practice to build an all-for-one tourism demonstration zone in Ningxia.

It can be seen that the relevant practice in Ningxia is relatively perfect. The relevant research of scholars mainly focuses on the suggestions and countermeasures for local development in combination with the conditions and current policies of Ningxia tourism, but there is no comprehensive research summary on its policy and implementation path.

\section{Survey of Research Area and Research Design}

\subsection{Survey of the Study Area}

In recent years, China's tourism has come into a mass tourism era, where backpacking and road trip begin to emerge. Tourism plays a more extensive role in the economic and social development as a comprehensive industry. Before the introduction of all-for-one tourism, Ningxia has begun to pay attention to the development of tourism, which has been changing from weak to strong, whose status in society and economy has been continuously improved with great contribution to the economic development in Ningxia and becomes one of the fastest industries. In 2015, the total number of domestic and foreign tourists receptions reached 183,948,800, an average annual increase of $15 \%$ compared with the year 2012; the region's tourism revenue increased from $4.31 \%$ in 2012 to $5.56 \%$ in 2015, the rate of the added value of the third industries rose up to $12.46 \%$ in 2015 from $10.77 \%$ in $2012^{2}$. Therefore, tourism has become one of the pillar industries in Ningxia (as shown in Figure 1).

Since the construction of the all-for-one tourism demonstration zone, Ningxia Hui Autonomous Region has achieved a lot in tourism which has become a new way of poverty alleviation in the poverty-stricken area. The brand, "Jiangnan of the Frontier - Magical Ningxia”, has been deeply rooted in people's hearts, because the quality of tourism services has been continuously improved by the promotion of the 10-Million projects. And the number of tourists in Ningxia and the total income of tourism are constantly increasing growth (Figure 2).

From the late of 2015 to 2017, the total number of domestic and foreign tourists coming to Ningxia Hui Autonomous Region increased from 184.148 million to 31.302 million. The total tourism revenue increased from RMB16.13 billion to RMB 27.8 billion. The total number of tourist reception and tourism income both achieved more than $20 \%$ growth for the first time in 10 years ${ }^{3}$.

The construction of all-for-one tourism demonstration zone has achieved remarkably, and its experience provides valuable reference for other places. Therefore, it is of great significance to summarize the policy regulation and implementation path of Ningxia.

\subsection{Research Design}

In the research, the author mainly applies the qualitative analysis method to

${ }^{2}$ Data from Ningxia tourism administration network.

${ }^{3}$ Data from "2018 Tourism Work Report of the Region”. 


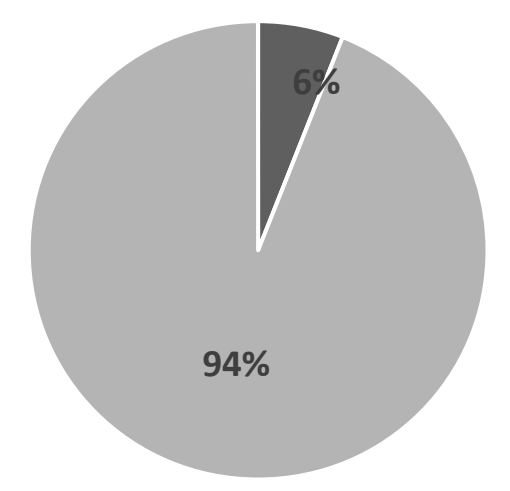

- Tourism Other industries

Figure 1. The figure for 2015 tourism revenue as a percentage of regional GDP.

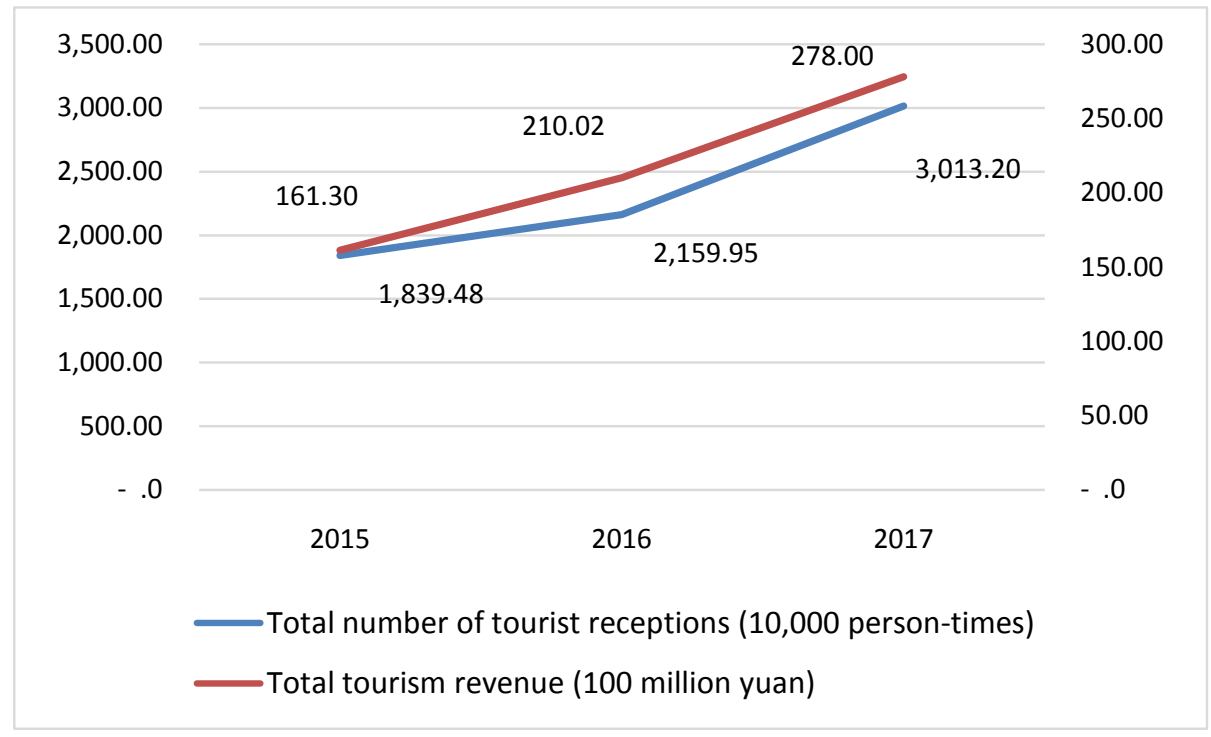

Figure 2. 2015-2017 Ningxia tourism development statistics.

analyze the relevant policies and measures of Ningxia's development of all-for-one tourism with Nvivo 11 qualitative analysis software. First, it summarizes the original qualitative data into meaningful data which is easy to manage, and then forms codes. This process is represented in Nvivo 11 as the establishment of free nodes and tree nodes. In this paper, the specific measures embodied in the relevant policy materials are initially conceptualized in Nvivo to form a 3rd-level node, which is open coding. Then, through the second review of the formed open code, the relationship between concept generics is determined to establish a 2nd-level node to determine the spindle coding; finally, based on the spindle coding, the "core class" is summed up, and then establish a 1st-level node, which is the selection code. By coding of the original materials layer-by-layer, the relationship of Ningxia's policy measures for creating the all-for-one tourism demonstration zone can be more clearly reflected, which facilitates the analysis of relevant policy regulations and summarizes of the implementation path. 


\section{Ningxia All-for-One Tourism Practice Analysis and Discussion}

\subsection{Policies and Coding Analysis}

Starting with policies drafted by Ningxia Hui Autonomous Region's in recent years, the author selects eight policy materials with relatively comprehensive measures as the material source, and employs Nvivo to encode the specific policy measures embodied in it to form nodes and build affiliation. The nodes are made up of three levels, and the 3rd-level nodes are specific measures after conceptualization based on the original materials. The 2nd-level nodes are derived from the conceptual generics obtained according to the requirements of the national development all-for-one tourism guidance. And the 1st-level nodes are based on the 2nd-level nodes. In this process, the author uses Zhang Hui's understanding in "Rational Thinking of All-for-one Tourism" for reference, that is, all-for-one tourism should not be understood from the perspective of "all", but should be explained from the perspective of "domain". The realization of "complete domain tourism", and "domain" can be divided into space domain, industrial domain, factor domain and management domain. And the development of all-for-one tourism should be complete in the four domains [23]. The author believes that this statement properly illustrates the connotation of all-for-one tourism and provides a more scientific and comprehensive approach to the analysis of policy measures. Therefore, in the process of constructing the 1st-level node, the author uses this theory and takes those four factors including domain of space, industry, factor and management into consideration as the important specific domains for the construction of all-for-one tourism demonstration zone, and then corresponds them to the specific measures (seeing Figure 3).

By arranging the nodes established in Nvivo, the following coding table can be obtained (seeing Table 1). The 3rd-level node covers 28 open codes, which shows the specific working measures of constructing the demonstration zone; the 2nd-level node covers 8 spindle codes, which reflects the degree of compliance between Ningxia specific measures and national requirements; The final 4 core generics covered in 1st-level node are the choice of coding. The code table can clearly reflect the relevant measures taken by the state for different development areas of the whole country and the corresponding efforts made by Ningxia.

On the base of the analysis of the coding table, the relevant policies for the establishment of the all-for-one tourism demonstration zone in Ningxia are relatively comprehensive. The specific measures are in lined with the relevant requirements in the "Guiding Opinions on Promoting the Development of All-for-one Tourism" and are consistent with the national idea. The "Guiding Opinions on Promoting the Development of All-for-one Tourism" clearly sets the overall target which is to realize comprehensive tourism development, qualification of tourism supply, maximization of tourism benefits and standardization of tourism management. The author summarizes this relationship as in Figure 4, which shows the effects and internal relationship between the specific 


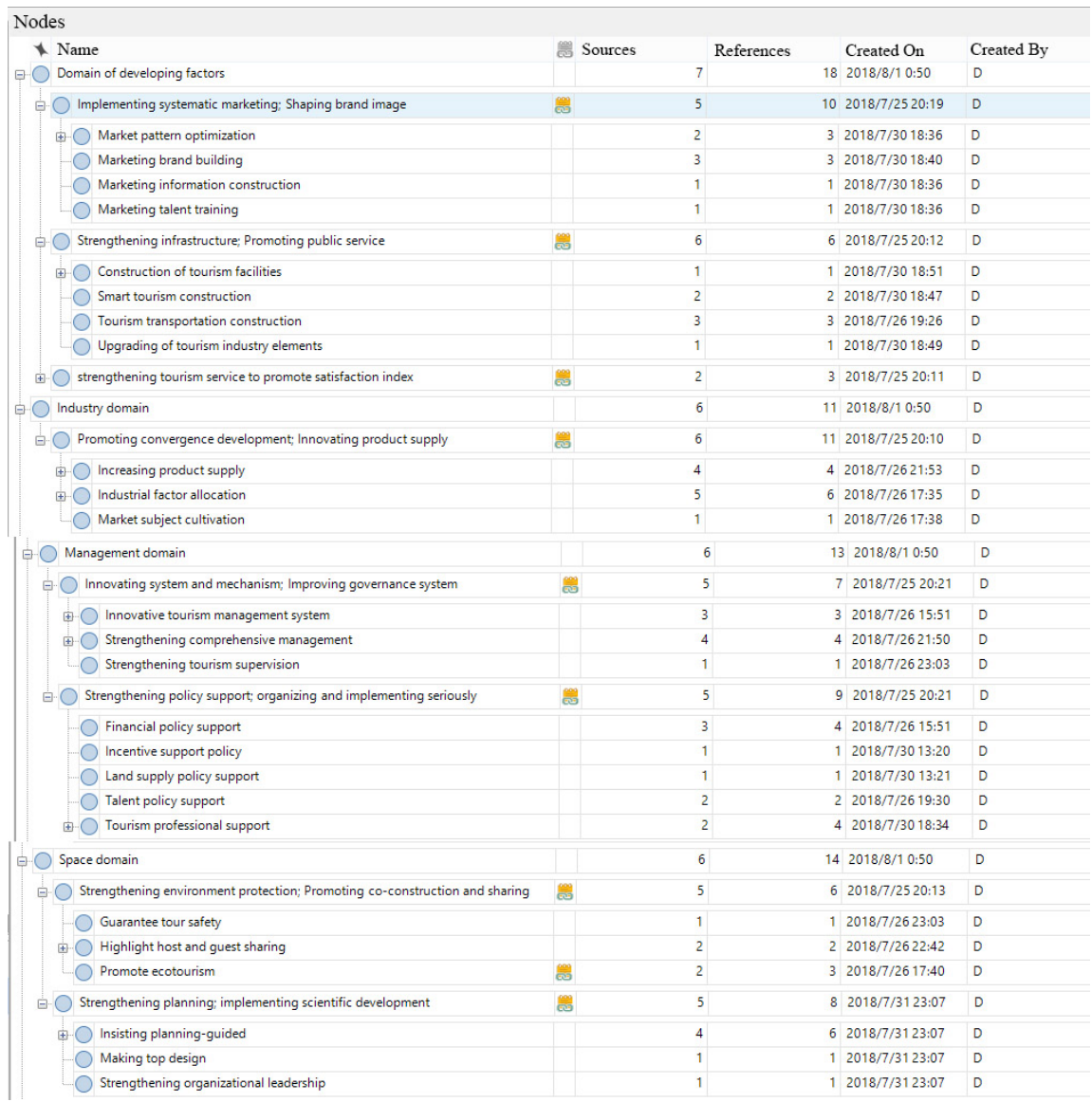

Figure 3. Node relationship of Ningxia's promotion of all-for-one tourism policy measures.

Table 1. Ningxia all-for-one tourism policy code table.

\begin{tabular}{|c|c|c|}
\hline Open coding & Spindle coding & Selection code \\
\hline Innovative tourism management system & \multirow{3}{*}{$\begin{array}{l}\text { Innovating system and mechanism; } \\
\text { Improving governance system }\end{array}$} & \multirow{8}{*}{$\begin{array}{l}\text { Management } \\
\text { domain }\end{array}$} \\
\hline Strengthening tourism supervision & & \\
\hline Strengthening comprehensive management & & \\
\hline Financial policy support & \multirow{5}{*}{$\begin{array}{l}\text { Strengthening policy support; } \\
\text { organizing and implementing } \\
\text { seriously }\end{array}$} & \\
\hline Talent policy support & & \\
\hline Land supply policy support & & \\
\hline Incentive support policy & & \\
\hline Tourism professional support & & \\
\hline Upgrading of tourism industry elements & \multirow{4}{*}{$\begin{array}{l}\text { Strengthening infrastructure; } \\
\text { Promoting public service }\end{array}$} & \multirow{9}{*}{$\begin{array}{c}\text { Domain of } \\
\text { developing factors }\end{array}$} \\
\hline Tourism transportation construction & & \\
\hline Construction of tourism facilities & & \\
\hline Smart tourism construction & & \\
\hline Standardized tour services & \multirow{3}{*}{$\begin{array}{l}\text { strengthening tourism service to } \\
\text { promote satisfaction index }\end{array}$} & \\
\hline Optimizing tourism towns & & \\
\hline Improving tourism elements & & \\
\hline Marketing brand building & \multirow{2}{*}{$\begin{array}{l}\text { Implementing systematic } \\
\text { marketing; Shaping brand image }\end{array}$} & \\
\hline Marketing talent training & & \\
\hline
\end{tabular}




\section{Continued}

\begin{tabular}{|c|c|c|}
\hline Market pattern optimization & & \\
\hline Marketing information construction & & \\
\hline Industrial factor allocation & \multirow{3}{*}{$\begin{array}{l}\text { Promoting convergence } \\
\text { development; Innovating product } \\
\text { supply }\end{array}$} & \multirow{3}{*}{ Industry domain } \\
\hline Market subject cultivation & & \\
\hline Increasing product supply & & \\
\hline Strengthening organizational leadership & \multirow{3}{*}{$\begin{array}{l}\text { Strengthening planning; } \\
\text { implementing scientific } \\
\text { development }\end{array}$} & \multirow{6}{*}{ Space domain } \\
\hline Insisting planning-guided & & \\
\hline Making top design & & \\
\hline Guarantee tour safety & \multirow{3}{*}{$\begin{array}{l}\text { Strengthening environment } \\
\text { protection; } \\
\text { Promoting co-construction and } \\
\text { sharing }\end{array}$} & \\
\hline Highlight host and guest sharing & & \\
\hline Promote ecotourism & & \\
\hline
\end{tabular}

Innovating management
system;
Strengthening supervision
and control

Financial support; talent support; land supply policy support;

incentive and supportive policies; professional support

upgrading of tourism industry elements; Tourism transportation construction; supporting facility construction; smart tourism construction

Standardize tourism services; Optimizing tourism towns;

Improving tourism elements

Marketing brand cultivation; marketing talents training; Market pattern optimization; marketing informatization

Factors allocation; marketing subject cultivating;

increasing product supply

Organization and leading;

Top-level design

keeping tourist safety; highlight sharing;

promoting ecotourism

Figure 4. Relationship between Ningxia's all-for-one tourism-related policies and development goals. 
development measures and the overall target of tourism development in NingXia.

\subsection{Policy Regulations for Ningxia All-for-One Tourism Demonstration Zone}

In the research design section, by comparing the certain measures with relevant national requirements in various development fields, the authors concluded that Ningxia's policy are relatively complete, and these policies in implementation helped a lot to the construction of demonstration area. In order to further explore the policy path, the author takes Ningxia Yinchuan Xixia District as an example to further analyze the policy and regulation.

As the capital city of the autonomous region, Yinchuan City has achieved gratifying results in tourism developing, which was chosen as one of "the top ten leisure destinations in China" in CCTV's program of your favorite tourist spot in May 2017. While in the third national tourism promotion conference in August 2017, Yinchuan became the first batch of the Top Ten China Tourism and Leisure Demonstration Cities, which was the only one in the Northwest of China. The achievement is closely related to Ningxia's long-term policy of taking advantage of its own ecological and cultural resources, attaching importance to planning and guidance, highlighting regional features, and vigorously developing all-for-one tourism. Among them, Xixia District has made great progress thanks to tourism. In 2017, Xixia District received a total of 6.1 million tourists, achieving a comprehensive tourism income of RMB4.98 billion. Tourism reception and its whole income increased by $21.4 \%$ and $25.8 \%$, and total tourism revenue accounted for $15.1 \%$ of GDP which got it awarded the "Top Ten Tourism Potential Counties" and "Hometown of China Helan Inkstone". As the first batch of demonstration zone, the experience of Xixia District is pretty typical.

In the process of development, Xixia District attached great importance to guiding planning and policy support, sticking to the government's leadership, and issued the "Xixia District Tourism Development Plan (2017-2030)" and "Xixia District Suggestions on Speeding up All-for-one Tourism Development", and a series of relevant policies and documents to improve the top-level design and to ensure the smooth implementation in the region. As in the process of the plan, Xixia District completed the planning of industrial projects such as Zhenbeibao Town and other local-featured small towns and wine industries, established cultural tourism industry project library in the region, and promoted the whole tourism with high-quality projects [24]. At the same time, Xixia District strengthened the infrastructure construction in the district. The toilet alliance campaign in the district fully promoted toilet revolution and steadily improved the quality of infrastructure in the district. In accordance with the requirements recommended by the Tourism Commission of the Autonomous Region, Xixia District promotes the integration and development of the tourism industry with the theme of "Tourism +", continuously extends the industrial chain and ${ }^{4}$ Data from Ningxia tourism administration network. 
enriches the supply of tourism products. For example, as tourism + culture has been gradually deepened, Xixia Imperial Tombs was applied for World Cultural Heritage, the 5A-level scenic spot of Helan Mountain rock painting was build, and film and TV productions such as "Wolf King" was made. And a series of sports tourism activities such as the New Year's Ascending Fitness Conference was successfully held to make tour + sports special and fine. By making full use of Ningxia's suitable climatic conditions, tourism + agriculture was well-developed, and Ningxia wine culture tourism was vigorously developed... In the implementation of this series of measures, Xixia District's practice in tourism marketing publicity is particularly worthy of reference. It not only carefully planned the Xixia Folk Park Hot Air Balloon Tourism Festival and other activities to attract tourists, cooperated with Xinhuanet and other media platforms to carry out propaganda, but also explored the establishment of a large tourism business alliance, which enabled 22 scenic spots, travel agencies and commercial enterprises to construct a pattern of big tourism of "group operation, bundled publicity, overall linkage".

The initial achievements of the establishment of demonstration zone made Xixia District quickly launch follow-up planning. In addition to further deepening the above measures, Xixia District further emphasized the importance of tourism supervision. The tourism market supervision, and tourism safety guarantee, the construction of credit system, Xixia District gradually covers tourism supervision to all aspects, and provides a favorable environment for the development of Xixia District's tourism.

These correct and reasonable policy regulations are important guarantees for the development of tourism in the whole Xixia District. The implementation of these regulations can be regarded as a microcosm in the process, namely, paying attention to planning and tourism supervision, emphasizing concrete implementation, and promoting industrial integration. The achievements in Xixia District reflect the effects of the policy measures proposed by Ningxia, and provide practical proof for further summarizing relevant policy paths.

\subsection{Ningxia's Policy Path for All-for-One Tourism Demonstration Zone}

The successful practice of Xixia District positively verified the correctness of its development policy. Based on the relevant practices, the policy regulations and implementation paths for Ningxia are summarized as follows in the aspects of spatial, administrative, elemental, and industrial domains embodied in the coding table.

Firstly, a reasonable plan with a comprehensive and systematic vision in the space domain and the management domain is to be made. Ningxia has successively issued policies and measures such as the Thirteenth Five-year Tourism Development Plan of Ningxia Hui Autonomous Region, the Opinions on Accelerating the Development of All-for-one Tourism, and other measures showed its scientifically understanding and planning for all-for-one tourism develop- 
ment. However, it should be pointed out that in the Thirteenth Five-year All-for-one Tourism Development Plan, Ningxia defined the development mode of "all spots, all industry, all the time, and all people" as the spatial development strategy of Ningxia's all domains. The focus of the entire tourism construction is still on the "all". Liu Jiaming pointed out the deficiency in understanding in the paper of Background, Misunderstanding and Hand-holding of Constructing All-for-one Tourism, which requires Ningxia to correct and improve in the later development.

Secondly, according to the existing plan, the policies should be refined into specific tourism elements of the factor domain to ensure the implementation of the plan, which includes tourism products, services, public infrastructure, marketing and other relevant elements. In the process, Ningxia attaches great importance to the cultivation and construction of tourism elements, such as tourism product innovation, improvement of tourism service quality, infrastructure construction and marketing promotion. Ningxia insists on the development of quality and continuously improves the tourism elements. Cultivating and building has laid a solid foundation for the development.

Thirdly, it is demanded to continuously promote the integration and development of the tourism industry and innovate the tourism development format. The completion of the factor domain will eventually become an inexhaustible motivation for the industrial domain. In this circumstance that the development of tourism elements is becoming more and more perfect, Ningxia actively promotes the integration and development of the tourism and other industries, and injects new vitality to the tourism development + mode. Besides, by constantly promoting the integration of tourism and characteristic culture, advantageous industries and new lifestyles, Ningxia continuously innovates the tourism industry, expands new areas of tourism, and adds fresh vitality to the development of all-for-one tourism to realize the leap in the development of the entire tourism industry.

Fourthly, the support and supervision of tourism at the management level shall be attached importance to. After the initial rapid development, a positive and good environment is required to further improve the quality. In the process of exploration, Ningxia actively carried out tourism support policies including finance, talents, land and other issues. On the one hand, it constantly emphasized the importance of tourism supervision such as market governance and tourism safety. On the other hand, the development of tourism provides a good environment to escort the creation of the demonstration zone.

\section{Conclusions}

Through the above discussion on four fields of space, management, industry and elements, we analyze and summarize the experience path of Ningxia's development by the example of Yinchuan Xixia District. That is to say, the establishment of the all-for-one tourism demonstration zone is made up of four as- 
pects-1) having a master plan, 2) paying attention to the specific implementation of planning measures, 3 ) and at the same time vigorously promoting industrial integration, 4) strengthening tourism supervision-so that the emergence and development of new tourism formats can be ensured. Meanwhile, the qualitative analysis also shows that the policy path in Ningxia is consistent with the national level. On one hand, the summary of its experience is of great importance to the development in other regions. On the other hand, it has important significance for Ningxia to optimize policy measures, develop tourism and contribute to Ningxia's targeted plan according to the requirements of each development domain. Taking the factor domain as an example, in terms of tourism marketing, Ningxia can follow the example of the marketing concept of Spanish hierarchical development to continuously explore Ningxia's features and strengthen the image of tourism brands. In the terms of innovation of tourism products, it can learn from the experience of French wine tourism and explore tourism products in depth. The connotation culture closely combines tourism products with local culture, and strives to make its products become the carriers and spokespersons of regional culture [25] [26].

The all-for-one tourism is an inevitable trend in the development of China's tourism industry. Starting from the Ningxia Hui Autonomous Region's policy of developing all-for-one tourism, the author summarizes the experience path, which has certain theoretical and practical significance. Whether it is Ningxia or other areas, they should determine their own path based on local conditions, and continuously optimize specific measures to achieve their goal. However, this paper only stays at the level of qualitative analysis, and fails to introduce quantitative analysis methods to quantify the specific impact on the development of all-for-one tourism in different domains. Future research can be explored in this direction to identify the role of policy measures in Ningxia and the specific impact of this path on tourism development.

\section{Conflicts of Interest}

The authors declare no conflicts of interest regarding the publication of this paper.

\section{References}

[1] Yang, Z.Z. (2016) The Connotation and Development Stages of All-for-One Tourism. Tourism Tribune, 31, 1-2.

[2] He, J.M. (2016) Research on the Concept and Model of Tourism Development: Also on the Concept and Model of Tourism Development in the Whole Region. Tourism Tribune, 31, 3-5.

[3] Liu, J.M. (2016) Background, Misunderstanding and Hand-Holding of Constructing All-for-One Tourism. Tourism Tribune, 31, 7-9.

[4] Li, X.J., Ma, L. and Chen, L.J. (2016) Tourism Development in the Whole Country: Logic and Key Points. Journal of Tourism, 31, 22-24.

[5] Xing, J.H. and Shi, P.H. (2016) From Idea to Practice-Emphasis on Promoting the 
Development of All-for-One Tourism with Science and Technology Innovation. Tourism Tribune, 31, 5-7.

[6] Ma, B. (2016) Expansion of Tourism Field: Boundary and Policy Implications. Journal of Tourism Science, 31, 17-20.

[7] Dai, X.F. (2016) All-for-One Tourism: An Important Means to Realize Tourism to Lead and Deepen Reform. Tourism Tribune, 31, 20-22.

[8] Luo, W.B. (2016) An Analysis of the Development of Singapore's Tourism Policy. Tourism Overview, No. 11, 164-165.

[9] Singapore Parliament (1964) Singapore Tourism Board Act. Singapore Parliament, Singapore.

[10] Canseng, O. (2002) Contrasting Strategies: Tourism in Denmark and Singapore. Annals of Tourism Research, 29, 689-706. https://doi.org/10.1016/S0160-7383(01)00086-X

[11] Hioe, W. (2000) National Infocomm Strategy and Policy: Singapore's Experience. ICA Information No. 74: General Issue.

[12] Yao, G.Z., Huang, W. and Wang, X. (2013) Research on the Development of Tourism Information in Singapore. Journal of Nanjing University of Posts and Telecommunications (Social Sciences Edition), 15, 45-50.

[13] Fang, Z.Q. and Chen, X.H. (2007) The Function and Enlightenment of the French Tourism Office. World Geography Research, 16, 61-65.

[14] Chen, X.Q. and Shen, S.W. (2018) Research on French Tourism by Chinese Mainland Scholars. SAR Economics, No. 2, 57-62.

[15] Ramón de Areces (2002) 50 Años de Turismo. Centro de Estudios, Madrid.

[16] Lin, Y. (2015) How Spain Become a "Tourism Kingdom”. Tourism Overview, No. 12, 23-24.

[17] Wang, K. (2017) Research on the Development Countermeasures of Ningxia Cultural Tourism Industry Based on All-for-One Tourism Perspective. Commercial Economy, No. 7, 84-86.

[18] Zhang, L. (2016) Analysis of the Leading Role of Government in the Development of All-for-One Tourism. Modern Business Industry, 37, 126-128.

[19] Wang, L. and Liu, J. (2016) Research on the Construction of All-for-One Tourism Demonstration Zone in Ningxia. Ningxia Social Sciences, No. 4, 123-127.

[20] Yang, F. (2017) SWOT Analysis of Tourism Development in Ningxia Region. China Market, No. 24, 241-242.

[21] Shi, P. (2016) Exploration of Ningxia in All-for-One Tourism. New Business Weekly, No. 10, 39-43.

[22] Xu, L. and Wang, J. (2017) Research on Ningxia Tourism Driving Strategy from the Perspective of All-for-One Tourism. Ningxia Social Sciences, No. 6, 91-95.

[23] Zhang, H. and Yue, Y. (2016) Rational Thinking of All-for-One Tourism. Tourism Tribune, 31, 13-14.

[24] Wang, K. (2016) Reflections on the Development of Ningxia's All-for-One Tourism-Taking Xixia District of Yinchuan City as an Example. Frontier Economy and Culture, No. 7, 9-10.

[25] Charters, S. and Aliknight, J. (2002) Who Is the Wine Tourist? Tourism Management, 23, 311-319. https://doi.org/10.1016/S0261-5177(01)00079-6

[26] He, L. (2016) The Development of French Wine Tourism and Its Implications for China's Development. World Agriculture, No. 2, 162-165. 